\title{
MUSIC TECHNOLOGY IN EDUCATION THROUGH THE EYES OF STUDENTS-FUTURE PRIMARY SCHOOL TEACHERS
}

\author{
M. Dimitrov* \\ Faculty of Education, Trakia University, Stara Zagora, Bulgaria
}

\begin{abstract}
The questionnaire is a part of research which aims at revealing the attitudes of the students towards the application of music technology in education. The answers and summaries of the respondents give feedback which is necessary for the future teaching work on improving the educational process, which should be corresponding to the rate of the technology development.

The article attempts to get a clear picture of:

- the preferences, interests and attitudes of the students towards the music technology they use during their free time;

- expressing opinion about their possible application in primary school;

- identifying shortness of knowledge how to achieve educational results.

Participants in the research - students second and third year at Trakia University, Faculty of Education, PPSE (Preschool and Primary School Education) and PSEFL (Primary School Education with Foreign Language).

The presented information has summarizing-analytical importance, the conclusions and summaries are drawn only from the context of the questionnaire. The quantitative analysis of the empirical data is represented in percentage.
\end{abstract}

Key words: questionnaire, music technology, music.

\section{INTRODUCTION}

The use of computer technology in music in its essence is merging the bounds of different sciences into art. The dynamically increasing quantity of information directly influences this process and affects the development and improvement of technical devices and technology. The educational application of the symbiosis of computers and music puts forward a set of requirements for educators and learners. [1] Generally, they are related to the acquisition of higher computer literacy level, increased interest in computer sciences and profound knowledge in the field of music.

Different interpretations of the concept "music technology" reoccur in literary sources. [2, 3, 4, 5] Having in mind their multifariousness, it is clear that no precise definition of the concept is

\footnotetext{
${ }^{*}$ Correspondence to: Milen Dimitrov, Trakia University, Faculty of Education, Stara Zagora, email: milendimitrov6@gmail.com
}

relevant. A possibility for a thorough understanding of the processes and forms of functioning of music technology in educational context is given through summary.

The most general sense, which we mean when we use the concept, is the understanding of the processes of creating, saving, editing and listening to musical pieces with the help of computer and other electronic devices.

The present article is based on research which includes questionnaires exploring the opinions, and attitudes of the students /during 2013 and 2015/ towards the practical application of music technology in educational context. The comparative analysis of the empirical data shows the change of views of the groups of respondents participating in the research.

To achieve our aim we used two partially standardized questionnaires (on paper forms for the first phase and online for the second) which 


\section{DIMITROV M.}

consisted of 11 questions, previously formulated and arranged into a certain sequence. The questions are of "close test" type, with given answers; "close scaled" with an option to choose positive or negative degree of expression; "open" where the respondents share their personal views on the problems.

The questions in the questionnaire cards are conditionally divided into three large groups:

I. Questions specifying the students' interests regarding their music activities with computer and/or other electronic devices.

II. Questions related to the devices and tools which the participants in the questionnaire use for their musical needs.

III. Questions about the respondents' views on possible practical application of the music technology knowledge in the practical training of "PPSE".

The first questionnaire was completed in May, 2013 at the Faculty of education, Trakia university, Stara Zagora.

80 respondents took part in the research "PPSE" students, Bachelor's Degree, who did not participate in the music technology training.
The second questionnaire was completed in May, 2015 at the Faculty of education, Trakia university, Stara Zagora. 80 "PPSE" students, Bachelor's Degree took part in it and they participated in the music technology training. The questionnaire was developed in the system of distance education at Trakia E-university.

The comparative analysis of the data and summaries give feedback which is needed for the successful realization of the Music Technology Competencies forming process in students. The quantitative analysis of the empirical data is represented in percentage and number of answers. The presented information has summarizing-analytical importance, the conclusions and summaries are drawn only from the context of the questionnaire.

Only part of the received results are included in the article.

The first group of questions is oriented to the interests of the students regarding their practical music technology activities during their spare time. (Table 1)

Table 1. Favourite musical activities

\begin{tabular}{|c|c|c|c|}
\hline \multicolumn{4}{|c|}{ 1. Favourite musical activities } \\
\hline 2013 & & 2015 & \\
\hline Downloading music from the internet & 72 & Listening and watching videos & 60 \\
\hline Listening and watching videos & 52 & Music Sharing & 44 \\
\hline Music games & 19 & Playing with virtual musical instruments & 45 \\
\hline Music storage & 45 & Downloading music from the internet & 47 \\
\hline
\end{tabular}

There is an impression that the students change their level of interest in their favourite musical activities. Downloading music from the internet ranked first according to the participants in the questionnaire of 2013, but in the second questionnaire, the respondents placed it last. For them, listening and watching videos was the most common activity. It is worth pointing out the fact that music games were not mentioned in the answers of the participants in the questionnaire of 2015 .

Table 2. Technical devices
In order to find out what technical devices the participants in the questionnaire utilize to satisfy their musical needs, we asked them to tick the devices they use most frequently. It became clear from the collected data that the majority of respondents of 2013 prefer using computers. In second position, by percentage correlation, the respondents placed mobile phones and in third tablets. The second group of respondents pointed out the mobile phones as the most frequently used devices and computers came in second position. (Table 2; Chart 1)

\begin{tabular}{|l|c|l|l|}
\hline \multicolumn{3}{|c|}{ Technical devices } \\
\hline \multicolumn{2}{|c|}{$\mathbf{2 0 1 3}$} & & $\mathbf{6 5}$ \\
\hline Computers & $\mathbf{7 2}$ & Mobile phones & $\mathbf{2 0 1 5}$ \\
\hline Mobile phones & $\mathbf{4 1}$ & Computers & $\mathbf{5 6}$ \\
\hline Tablets & $\mathbf{2 3}$ & Tablets & $\mathbf{3 2}$ \\
\hline Portable players & $\mathbf{3 7}$ & Portable players & $\mathbf{1 2}$ \\
\hline
\end{tabular}


DIMITROV M.

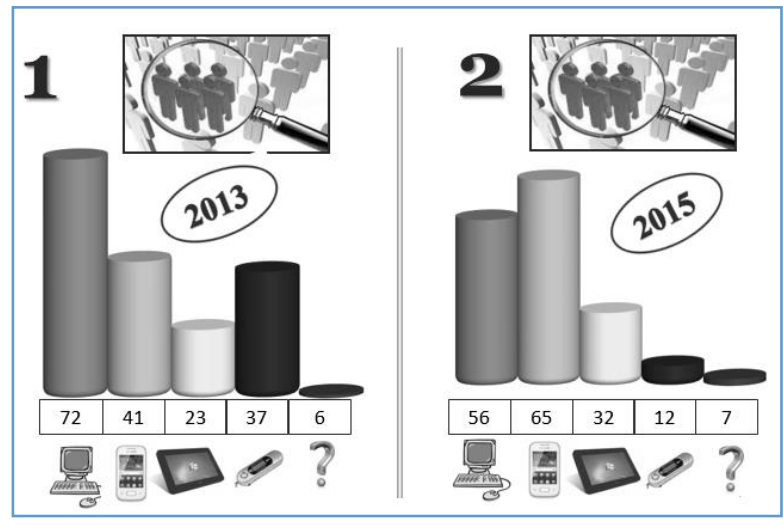

Chart 1. Technical devices
The empirical results show a relative parity of preferences for tablets in the answers of both surveyed groups.

It has to be noted that the question "Is music technology applicable to the education of students - future primary school teachers?" was answered in a positive way and showed students' eagerness to acquire knowledge and skills related to this topic, so that they can realize them in their future educational practice. (Table 3)

Table 3. Application of musical computer technologies in the education of students

\begin{tabular}{|l|l|l|l|}
\hline \multicolumn{2}{|c|}{ Is music technology applicable to the education of students - future primary school teachers? } \\
\hline \multicolumn{2}{|c|}{$\mathbf{2 0 1 3}$} & \multicolumn{2}{c|}{$\mathbf{2 0 1 5}$} \\
\hline Yes & $\mathbf{5 5 \%}$ & Yes & $\mathbf{6 0 \%}$ \\
\hline Limited & $\mathbf{2 2 \%}$ & Limited & $\mathbf{3 6 \%}$ \\
\hline No & $\mathbf{1 3 \%}$ & No & $\mathbf{5 \%}$ \\
\hline Not answer & $\mathbf{3 \%}$ & Not answer & $\mathbf{1 \%}$ \\
\hline
\end{tabular}

Insignificantly higher is the relative number of the answers "Yes" among students who participate in music technology training. We attribute this predominance of positive answers to the rediscovered benefits and motivation caused by the fact that the educational discipline is up-to-date and interesting. The negative answers are not to be neglected and they direct our attention towards the expression of certain inertial processes among the respondents' attitudes to the application of computers in education. (Chart 2)

In both surveys, the participants - future teachers define the fields of the application of music technology in the process of music education in primary school and order them in an identical way:

1. Demonstrations and presentations of educational content

2. Listening to music
3. Creative activities

4. Music games

5. Others (Table 4)

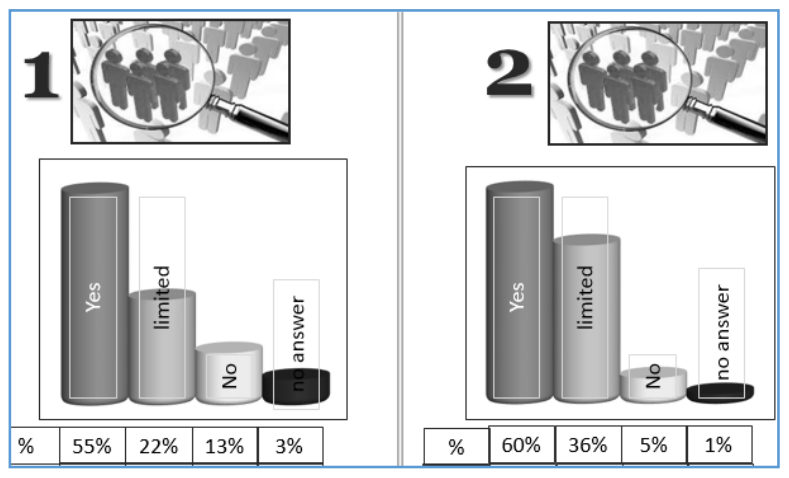

Chart 2. Application of musical computer technologies in the education of students

Table 4. Application of music technology in the process of music education in primary school

\begin{tabular}{|l|r|l|l|}
\hline \multicolumn{3}{|c|}{ Application forms } \\
\hline \multicolumn{2}{|c|}{$\mathbf{2 0 1 3}$} & \multicolumn{2}{c|}{$\mathbf{2 0 1 5}$} \\
\hline $\begin{array}{l}\text { Demonstrations and presentations of educational } \\
\text { content }\end{array}$ & $\mathbf{3 1 \%}$ & $\begin{array}{l}\text { Demonstrations and presentations of educational } \\
\text { content }\end{array}$ & $\mathbf{3 3 \%}$ \\
\hline Listening to music & $\mathbf{1 9 \%}$ & Listening to music & $\mathbf{2 6 \%}$ \\
\hline Creative activities & $\mathbf{1 4 \%}$ & Creative activities & $\mathbf{1 7 \%}$ \\
\hline Music games & $\mathbf{1 7 \%}$ & Music games & $\mathbf{1 9 \%}$ \\
\hline Others & $\mathbf{1 9 \%}$ & Others & $\mathbf{5 \%}$ \\
\hline
\end{tabular}


In the answers of the students from both groups is not found a statistically significant difference related to the positioning of the demonstrations and presentations of educational content and music games. (Chart 3)

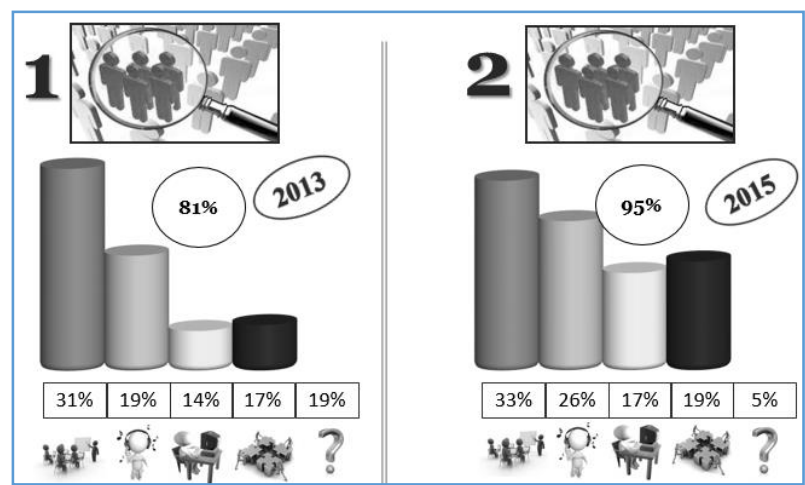

Chart 3. Application of music technology in the process of music education in primary school

In an open interview to specify some of the answers to the posed questions, the majority of the interviewees share that they interpret "demonstration" as the use of music technology for:

-creating and using musical fragments (timbres of musical instruments and voices);

-notation examples and elements of notation writing;

-editing and discussing the changes of musical pieces (in tempo and tonality) with students.

We asked the respondents to take "a momentary photo" of the condition and to mark the degree of computer usage /from 1 to $5 /$ in music education in primary school. It was clear from the collected data that the majority of the participants in the questionnaire consider the use of computers in education insufficient. In response to the opinions students expressed, we can note that there is a certain increase in the use of computers in the education of primary school pupils, which is shown also in the enclosed table. (Table 5; Chart 4) The received results lead us to summarize that the presence of computers and technology in educational field grows stronger. It is logical to assume that the students' opinions on this matter are very critical and directly dependent on their average age (23) and their high expectations coming from their daily musical activities involving computers or other microprocessor devices. This assumption is also confirmed by the answers to the question: "How do you assess your music technology literacy?", where the predominant answers were "Good" in both of the surveyed groups. (Chart 5) The answers to this question directly correspond to the given favourite activities which students chose in previous question. Young people are particularly interested in technology improvement and extremely sensitive about enhancing their own competencies. They use microprocessor and music devices, download, save, exchange and edit music.

Table 5. Degree of music technology usage in teaching in primary school

\begin{tabular}{|l|l|l|l|}
\hline \multicolumn{4}{|l|}{ Degree of application } \\
\hline 2013 & \multicolumn{2}{l|}{2015} \\
\hline 1 & $21 \%$ & 1 & $15 \%$ \\
\hline 2 & $37 \%$ & 2 & $23 \%$ \\
\hline 3 & $22 \%$ & 3 & $37 \%$ \\
\hline 4 & $17 \%$ & 4 & $20 \%$ \\
\hline 5 & $3 \%$ & 5 & $5 \%$ \\
\hline
\end{tabular}

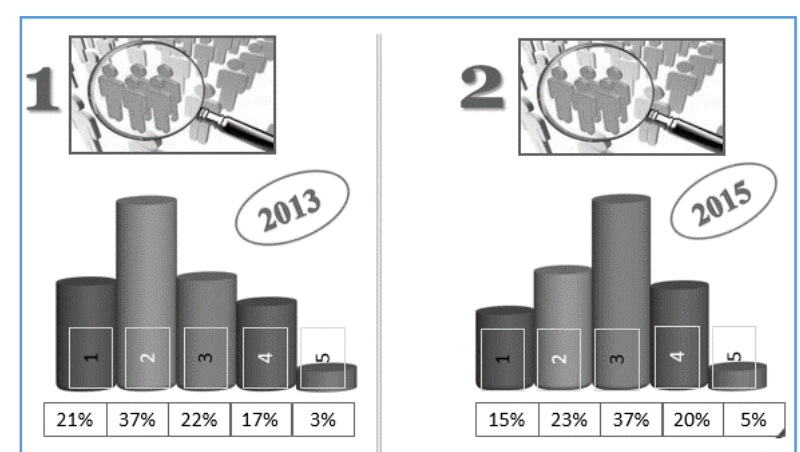

Chart 4. Degree of music technology usage in teaching in primary schoo

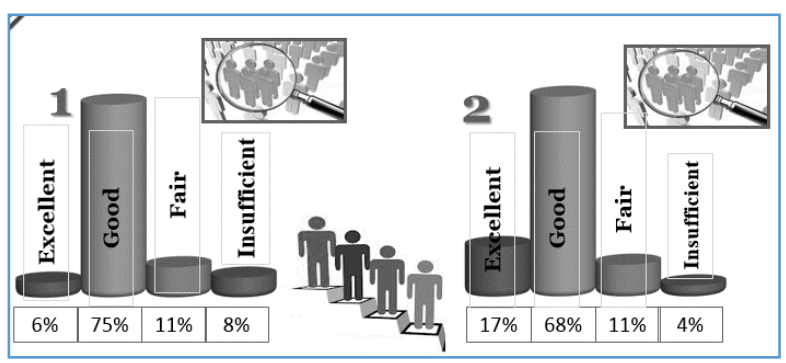

Chart 5. How do you assess your music technology literacy?

\section{CONCLUSIONS}

The fact that the students show great interest in music technology during their course of education and also in their spare time is indisputable. Their preferences for the technical devices and the music technology activities are directly dependent:

-On the rate of technology development and the current state of computer market;

-on their experiences in working with computers and technical devices, the software they are trained and familiar with;

-on their social and family environment; 
-on the influence of the means of mass communication and media.

In order options to be realized for the application of music technology in students' education, the pedagogical practice should:

-Adapt flexibly to the way of balance in using computer technology and knowledge in the field of music theory;

-be adequate for the achievements and improvements of music technology;

-be directly involved in school education during the training of the future teachers; -initiate striving to overcome certain inertial processes from the past.

\section{REFERENCES}

1. Andrew Brown, Music Technology and Education,2014

2. Francis Rumse, Desktop Audio Technology: Digital audio and MIDI, 2003

3. Simon Holland, Katie Wilkie,Music and Human-Computer Interaction, 2013

4. Georgiev A., Fundamentals of computer music technology, Sofia, 2004

5. Georgiev A., Musical computer literacy, Sofia, 2005 